\title{
SUN-ANGLE EFFECTS ON THE RED AND NEAR INFRARED REFLECTANCES OF FIVE DIFFERENT CROP CANOPIES
}

\author{
by
}

Daniel Lord

Department of Fundamental Sciences, Université du Québec à Chicoutimi

Raymond L. Desjardins

LRRC, Research Branch, Agriculture Canada

and

Pierre A. Dubé

Department of Phytology, Faculty of Agricultural Sciences and Food, Université Laval

\section{RÉSUMÉ}

Le présent article décrit une étude des relations entre les variations quotidiennes de l'angle du soleil ainsi que des réflectances dans le rouge et le proche infrarouge mesurées tout au long d'une saison de récolte sur différents types de couverts végétaux. Cinq couverts végétaux de structure différente ont été semés: blé (rangs NNO-SSE à intervalles de 0,18 et 0,35 mètres), orge (rangs NNO-SSE à intervalles de 0,18 mètre), maïs (rangs NNO-SSE à intervalles de 0,46 mètre) et tournesol (rangs N-S à intervalles de 0,92 mètre). Chaque couvert végétal a été semé à trois densités différentes de manière à pouvoir mesurer la variabilité au sein de chaque espèce. Les réflectances spectrales ont été mesurées à la position nadir à l'aide d'un capteur fixé à une plate-forme au sol.

En général, les variations de l'angle du soleil touchaient davantage les réflectances dans le rouge que les réflectances dans le proche infrarouge. Pour chaque culture, les couverts ayant l'indice de surface foliaire (ISF) le moins élevé ont systématiquement donné la plus grande variation au niveau des réflectances spectrales. Par contre, entre les diverses cultures, la variation de l'angle du soleil sur les réflectances des couverts végétaux était fonction de la structure du couvert. Les réflectances rouges recueillies au-dessus du maïs et du tournesol avec un ISF de 6 étaient insensibles aux variations de l'angle du soleil, tandis que celles mesurées au-dessus des tournesols variaient substantiellement lorsque l'ISF était aux environs de 4. Cette différence entre les deux cultures peut s'expliquer par la présence d'une plus grande distribution foliaire horizontale comparativement à la surface verticale offerte par le couvert de maïs, puisqu'un couvert ayant une distribution foliaire horizontale se rapproche davantage d'une surface lambertienne. La différence dans la largeur et l'orientation des rangs pourrait aussi expliquer certaines de ces différences. Les couverts de blé semés en rangs à intervalles de 0,35 mètre ont donné des variations de réflectances dans le rouge plus grandes dans une journée que ceux semés à intervalles de 0,17 mètre. Les réflectances maximales dans le rouge se produisaient toujours lorsque le soleil était en ligne avec les rangs. Le fait que la plupart des variations rapides des réflectances dans le rouge se produisaient à ce moment particulier de la journée a aussi confirmé qu'il existe une forte corrélation entre la direction et la largeur des rangs et la position du soleil dans le ciel. Cette étude a démontré que l'ampleur de l'incidence des variations de l'angle du soleil sur les réflectances spectrales des couverts végétaux est fonction de l'espèce, du mode de semence, de la longueur d'ondes de la bande et des conditions du ciel.

\section{SUMMARY}

The objective of this paper is to study relationships between daily variations in sun angles and red and near infrared reflectances measured throughout a growing season over different types of crop canopies. Five architecturally different crop canopies were planted: wheat (NNW-SSE rows $0.18 \mathrm{~m}$ and $0.35 \mathrm{~m}$ apart), barley (NNW-SSE rows $0.18 \mathrm{~m}$ apart), corn (NNW$S S E$ rows $0.46 \mathrm{~m}$ apart), and sunflower ( $N-S$ rows $0.92 \mathrm{~m}$ apart). Each canopy was planted at three different densities in order to add intraspecies variability. Spectral reflectances were measured with a sensor in the nadir position located on a ground platform.

Changes in sun angles usually affected the red more than near infrared reflectances. Within each crop, the canopies with the lowest LAI always showed the largest variations in spectral reflectances. But among the crops, the importance of changing sun angles on crop canopy reflectances varied with the architecture of the canopy. Red reflectances collected over corn and sunflower at LAI of 6 were insensitive to changes in sun angles, while those collected above sunflower showed significant differences when LAI was around 4. The higher proportion of horizontal foliar area compared to the vertical one in corn canopies could account for this difference between the two crops, since a canopy with horizontal foliar distribution is a nearer approximation of a lambertian surface. The differences in row width and orientation could also explain some of these differences. Reflectances of wheat canopies planted with rows $0.35 \mathrm{~m}$ apart showed larger red reflectance variations within a day than those planted $0.17 \mathrm{~m}$ apart. The maximum red reflectances always appeared when the sun was in line with row direction. The fact that most rapid variations in red reflectances were occurring around this particular time of the day also confirmed that there is a strong interaction between row direction and width with the position of the sun in the sky. The magnitude of the effect of the variations of sun angles on crop canopy spectral reflectances was shown to be dependent on the species, planting patterns, wavelength band, and sky conditions. 


\section{INTRODUCTION}

Ground-based measurements of plant canopy spectral reflectances are considered useful for estimating crop canopy characteristics (i.e., Jackson et al, 1980; Asrar et al, 1984; Weiser et al, 1986; Goel and Grier, 1987). However, the daily or seasonal variations of some non-vegetative factors influence the relative proportion found between the four elements giving the total reflected energy from a canopy, that is, the proportion of sunlit and shaded areas of soil and of vegetation (Richardson et al, 1975; Jackson et al, 1979b). As previously reported for wind and clouds (Lord et al, 1985a,b), changes in angular variables often introduce variations in the proportion between sunlit and shaded soil and plants. These variations caused by other factors than the vegetation itself influence the spectral reflectance values of a given plant canopy measured at a given time with a sensor in most positions (Egbert and Ulaby, 1972; Ranson et al, 1985a,b). The solar elevation and azimuth angles, the view-angle of the sensor and its azimuth, and the row direction are all angles which can have a bearing on plant canopy reflectance measurements (Kimes et al, 1980).

The angular effects of the azimuth of the sun, the row direction, and the sensor position may be assumed to be negligible when the reflectances are measured above a uniform and dense canopy with a sensor in the nadir position. However, the daily variations in the solar elevation angle often continue to introduce non-vegetative variability in the canopy reflectance data. For example, Egbert and Ulaby (1972) considered a dense stand of grass without rows as a lambertian type surface only for solar elevation angle above $35^{\circ}$. Kollenkark et al (1982) found only negligible variations between the number of red and near infrared reflectance factors measured above a high density soy bean canopy without rows during a period when the solar elevation angle ranged from $35^{\circ}$ to $65^{\circ}$. Jackson et al (1979a) obtained similar results for a wheat canopy without rows at a solar elevation angle above $30^{\circ}$, while Duggin (1977) found an effect of this angle for a wheat canopy without rows, an effect that was stronger on the near infrared reflectance factor $(800-1100 \mathrm{~nm})$ than on the red one (600-700 nm). Duggin did, however, work with wheat canopies planted at lower density. Differences in the architecture of the canopies can also introduce variability in the reflectance data (Jackson and Pinter, 1986). For example, Pinter et al (1985) found that red and near infrared reflectance factors of planophile varieties of wheat canopies were higher and less influenced by changes in sun zenith and azimuth angles than reflectance factors collected over erectophile varieties.

The situation is quite different for row canopies, as the reflectances of incomplete canopies show a greater dependence on sun and view geometry, particularly in the red (Ranson et al, 1985b). Jackson et al (1979a) stated that the lambertian assumption for wheat canopy planted in north-south rows agrees well only for the near infrared reflectance factor and only when the solar elevation angle is above $30^{\circ}$; this assumption does not hold for the red reflectance factor. Diurnal changes of more than 140 per cent were also observed in the red reflectance factor of soybean canopy planted in different row directions, while the near infrared one was, by far, less affected (Kollenkark et al, 1982). These authors also found a maximum red reflectance factor when the difference between the azimuth angle of the sun and the row direction angle reached zero. That means the interception of red incident light by the vegetative elements is minimal when the sun is directly above the rows of the canopy. With a different background color, Vanderbilt et al (1981) found a difference up to 230 per cent between the red reflectance factors measured above two soybean canopies with different row directions. These results indicate that, for canopies with rows and with low percentage ground cover, the azimuth angle of the sun and the row direction significantly influence the plant canopy reflectances measured with a sensor in the nadir position (Jackson et al, 1979a; Kollenkark et al, 1982). They also indicate that red reflectances are more affected by nonvegetative factors than near infrared ones.

The objective of this study is to demonstrate, using five crop canopies measured at different times during the growing season, the importance of sun angle and row direction variations on the spectral reflectances measured by a ground-based sensor in the nadir position. Two other objectives are to show the dependence of the magnitude of these variations with both the plant canopy architecture and the amount of green vegetation, and to demonstrate the difficulties to efficiently minimize the effects of angular factors in normalizing the crop canopy reflectance data collected at different times during a day or a growing season.

\section{MATERIAL AND METHODS}

\section{Experimental Conditions and Agronomical Measurements}

The data were collected in 1980 and 1981 at the Central Experimental Farm in Ottawa, Ontario. The crops were all planted on a fertilized Rubicon sandy soil. In 1980, wheat (Triticum aestivum L. var. Pitic 62) and barley (Hordeum vulgare L. var. Massey-Breeder No. 2) were planted on May 5 with NNW-SSE rows $\left(30^{\circ}\right.$ from $\mathrm{N}-\mathrm{S}$ axis) $0.18 \mathrm{~m}$ apart. Each plot of $10 \mathrm{~m}$ long and $8 \mathrm{~m}$ wide was divided in three sub-plots of $3.3 \mathrm{~m}$ long and $8 \mathrm{~m}$ wide planted at densities of $0.898,0.674$, and $0.449 \mathrm{hl} \mathrm{ha}^{-1}$. The wheat sub-plots were further divided into two sections of $3.3 \mathrm{~m}$ long and $4 \mathrm{~m}$ wide; every second row was removed on the north part to create three additional densities $(0.449,0.337,0.225 \mathrm{hl}$ ha $^{-1}$ with rows $0.35 \mathrm{~m}$ apart. The corn (Zea mays $\mathrm{L}$. var. Co-op 259) was planted at three different densities (54000, 47000 , and 40000 plants $\mathrm{ha}^{-1}$ ) on May 15 with NNW-SSE rows $0.46 \mathrm{~m}$ apart. In 1981, the sunflower (Helianthus annuus L. cv. Sigco 449) was planted at three different densities $(52000,42000$, and 30000 plants $\mathrm{ha}^{-1}$ ) on June 1 with N-S rows $0.92 \mathrm{~m}$ apart.

Observations on growth stages and measurements of percentage ground cover and green leaf area index (LAI) for each subplot were collected weekly throughout the growing season. The scales of Large (1954), Hanway (1966), and Schneiter and Miller (1981) were used to determine the growth stage of wheat and barley, corn, and sunflower respectively. Percentage ground cover was estimated by using vertical colour infrared photographs taken at $5 \mathrm{~m}$ above the ground. For wheat and barley, the green leaf area of 10 plants randomly chosen for each sub-plot was measured weekly using a portable area metre (Li-Cor, Model LI-3 000), while this measurement was made weekly on three plants per sub-plot for corn and sunflower. LAI was calculated from these green leaf area measurements.

\section{Spectral Measurements}

Spectral measurements were made with the field system described by Brach et al (1983). The system included a self-moving spectroradiometer for collecting the radiometric data. It travels on a movable track at a height of $3 \mathrm{~m}$, and data are transmitted through spectral filters to a silicon detector with a $8^{\circ}$ field-of-view, which has a spectral band width ranging from 350 to $1100 \mathrm{~nm}$. 
At ground level, the spectroradiometer integrates the spectral values of a $0.4 \mathrm{~m}$-wide strip of crops (Brach et al, 1983). The hemispherical incident radiation passed through a cosine-corrected collector, while the conical reflected radiation was directly measured by the detector through a hole with a $8^{\circ}$ field-of-view. The ratio of the reflected and incident energies gave the hemispherical-conical reflectance specific to the geometry of this instrument (Nicodemus et al, 1977). Between the two collectors and the detector, there was a filter wheel holding four $25 \mathrm{~mm}$-diameter interference filters with various central wavelength values and with half-band width around $10 \mathrm{~nm}$. The mechanism turning the filter wheel provided a $4 \mathrm{~s}$ exposure for each filter, $2 \mathrm{~s}$ for the measurement of the reflected radiation, and $2 \mathrm{~s}$ for the incident radiation. A positioning counter was used to identify the location of each radiometric measurement. All measurements were recorded on a magnetic tape.,

The central wavelength values of the two filters used in this study were $675 \mathrm{~nm}$ in the red (R) and $790 \mathrm{~nm}$ in the near infrared (NIR). The first one corresponds to a region of strong absorption by chlorophyll, while the near infrared value corresponds to a region of high reflectivity from leaf structures (Knipling, 1970).

\section{Data Analysis}

The numerous spectral reflectance data collected for each day were divided in periods of approximately $2000 \mathrm{~s}$, which corresponds to two complete passes above a given plot. This means that each spectral reflectance value found in this study was calculated from a sampling of 36 to 40 reflectance measurements collected at different locations over a sub-plot. For each period, the solar elevation and azimuth angles were calculated for the time that corresponds to the middle of the period (Walraven, 1978). The spectral data collection calendar is given in Table 1. The growth stage and the LAI range of the crops under study, as well as the solar elevation angle range during each day studied, are also shown in this table.

\section{RESULTS AND DISCUSSION}

\section{Trends for All Species}

Near infrared and red reflectances measured during a given day over the five crops under study are unequally affected by the variations of the densities of plants and the daily variations of sun angles. For the five crops at various growth stages, Figures 1 to 5 show LAI and row widths and the effects of daily variations in solar elevation angle on red and near infrared reflectances measured by a sensor in the nadir position. LAI variations were perfectly correlated with the densities for all crops at all growth stages. Therefore, the greatest LAI value shown on a figure always means the high density sub-plot, while the lowest indicates the sub-plot planted at the lowest rate. Only the reflectances collected over the highest and the lowest sub-plots are shown, with those collected over the middle one giving a graph located between the two extremes.

These figures show that some general trends are found for all species. As expected from previous works (i.e., Colwell, 1974), red reflectance values are usually smaller for dense canopies with similar sun angles. Except for barley, the opposite trend is found for the near infrared reflectance values. If the magnitudes of the differences calculated between reflectances measured at a specific solar elevation angle over two densities vary with species and their growth stage, these differences remain approximately the same within a given day of reflectance measurement.

The values of reflectances collected during a day over a specific density also vary with solar elevation angle for most of the days under study and for both wavelength bands, but there are more reflectance variations between densities than between solar elevation angles (Figures 1 to 5). The architecture of the canopy and the amount of green elements in it (LAI) are then the factors that account for the largest fraction of the total variability introduced in the plant canopy spectral reflectance measurements. These factors, which are fundamental to the comprehension of the radiation regime in a canopy (Ross, 1976), are very important in the interpretation of the spectral response of canopies for estimating a crop canopy parameter (Jackson and Printer, 1986). Asrar et al (1985) also concluded that the symmetric influence of solar illumination angle on estimated LAI from spectral reflectance measurements collected over wheat canopies was not as significant as the effects of asymmetric factors that were caused by management practices and/or the intrafield variability.

However, the reflectance variations caused by changes in sun angles are present for all crops except for corn, being more

Table 1

Spectral data collection calendar. SEAR means Solar Elevation Angle Range.

\begin{tabular}{llllll}
\hline Species & Date & Weather & SEAR $\left.{ }^{\circ}\right)$ & Growth stage & LAI range \\
\hline Wheat & $6-13$ & sunny with strong haze & $46-68$ & jointing & $1.0-3.0$ \\
$0.18 \mathrm{~m}$ & $6-25$ & warm and humid & $48-68$ & boot & $1.5-3.8$ \\
& $7-11$ & humid and stormy & $44-67$ & flowering & $0.8-1.7$ \\
& $7-25$ & sunny with cumulus & $47-64$ & milky ripe & $0.5-1.1$ \\
Wheat & $7-14$ & sunny with haze & $44-62$ & milky ripe & $0.5-1.0$ \\
$0.35 \mathrm{~m}$ & $7-31$ & sunny & $41-63$ & mealy ripe & $0.1-0.3$ \\
Barley & $5-29$ & sunny & $48-65$ & tillering & $0.5-1.0$ \\
& $6-05$ & sunny with slight haze & $46-68$ & jointing & $1.6-2.0$ \\
& $6-17$ & high cirrus & $46-68$ & stem extension & $2.1-4.0$ \\
& $8-05$ & sunny with haze & $45-61$ & blister & $0.0-0.0$ \\
Corn & $7-30$ & sunny, small cumulus & $44-63$ & silks emerging & $3.2-6.9$ \\
& $8-22$ & sunny with cumulus & $40-57$ & dough stage & $3.0-6.6$
\end{tabular}


important when red reflectances are measured over canopies of sunflower, barley at maturation stages, and wheat planted in wide rows. Then, its effect, which causes introduction of non-vegetative variability in the reflectance data collected during a day, should be minimized as much as possible when reflectance measurements collected at different times during a day or a growing season are collected for estimating crop canopy characteristics.

\section{Species Influence}

Corn and sunflower both have a relative foliage density area greater at the top of the canopies, but the proportion of horizontal foliar area compared to the vertical one is higher for corn than sunflower canopies (Ross, 1976). At the time of the reflectance measurements above these two canopies, all the densities were characterized by LAI ranging from 3.0 to 6.5 and percentage ground cover ranging from 90 to 98 per cent. Since the spectral reflectances of a dense canopy without rows are unaffected by the daily variations in sun angles when the sun is relatively high in the sky (Jackson et al, 1979a), the effects of this factor are then expected to be weaker on a high density than a low density row crop canopy. Furthermore, the magnitude of the effect of the solar elevation angle on the reflectances of a crop canopy that is characterized by a well-developed vertical leaf area distribution should decrease with an increasing amount of green vegetation because sunlit and shaded leaves become the sole reflecting surfaces, whatever the position of the sun in the sky.

For sunflower and corn canopies with the highest LAI, Figures 1 and 2 show that the effects of the daily variations in solar elevation angle on red reflectances are negligible. They act as a lambertian surface. For the lowest LAI values, significant red reflectance differences are measured above sunflower canopies for angles greater than $60^{\circ}$, while corn canopies are relatively insensitive to variations in solar elevation angle between 30 and $65^{\circ}$. The significant variations between consecutive reflectances measured above sunflower canopies at low LAI appear between 60 and $65^{\circ}$ (around noon), when the fraction of the sunlit soil is greatest (Figure 1). The red reflectances collected above corn canopies at low density do not show this pattern, even if these were characterized by smaller LAI than those measured for sunflower canopies at low LAI. This difference between the daily reflectance pattern of the two crops with similar height at the time of the measurement can be explained by a combination of three factors, all of these causing lower interception of the direct solar radiation by the sunflower canopies: 1) corn canopies have smaller row width than sunflower; 2) the angle of incidence of the direct solar radiation does not reach more than $66^{\circ}$ under our experimental conditions over these two crops (Table 1); and 3) canopies show architectural differences since the largest amount of horizontal green leaves are found at the top of the corn canopies (Ross, 1976), which means that corn canopies act more like a flat plate than sunflower canopies.

The combination of all these factors means that corn is characterized by a more effective percentage ground cover at the solar elevation angles found in this study. The result is a higher

Figure 2

Same as Figure 1, except row azimuth is $150^{\circ}$. Data were collected over corn canopies:

a) on 30 July at silks emerging; and

b) on 22 August at dough.

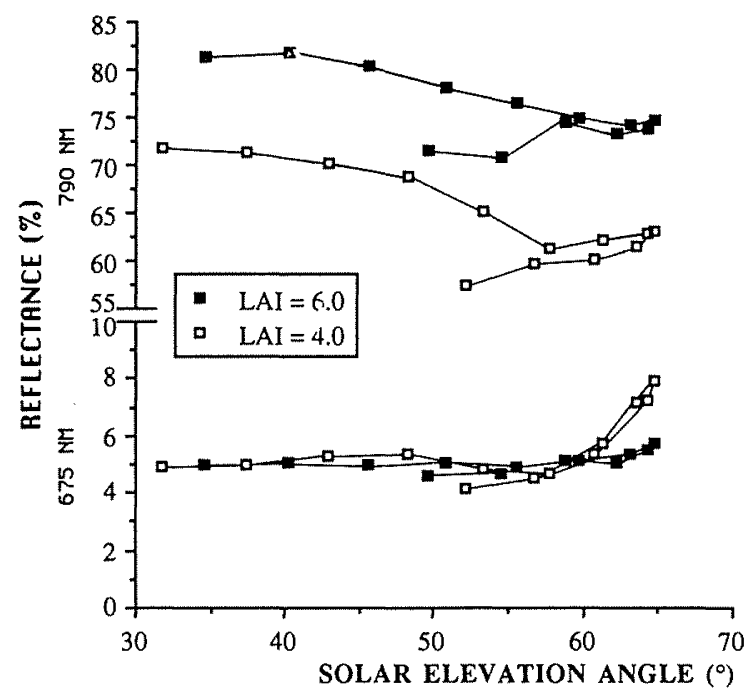

Figure 1

Red $(675 \mathrm{~nm})$ and near infrared $(790 \mathrm{~nm})$ reflectances for various solar elevation angles. Data were collected on 24 July over two sunflower canopies at flowering. Row azimuth is $180^{\circ}$. Standard deviations are less than or equal to the symbol heights.

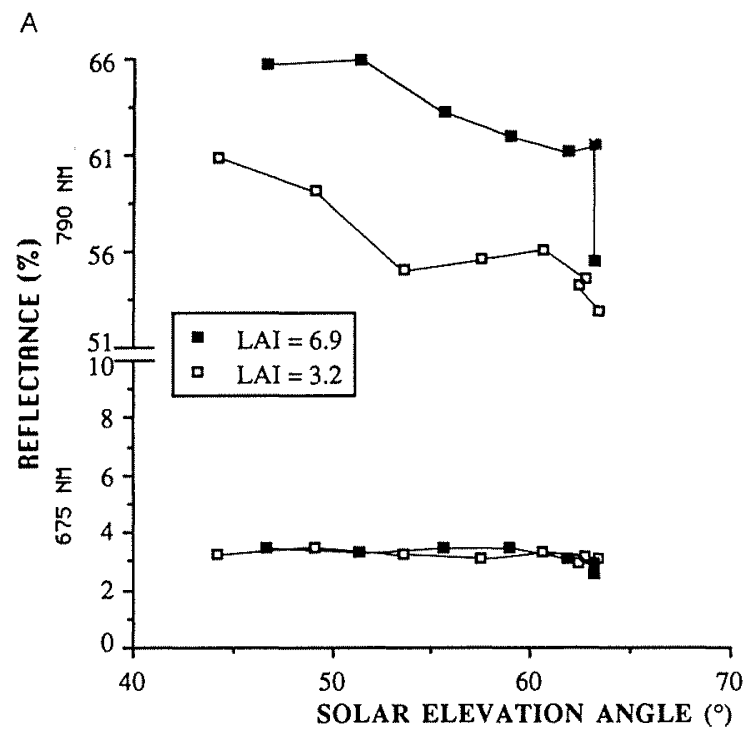

B

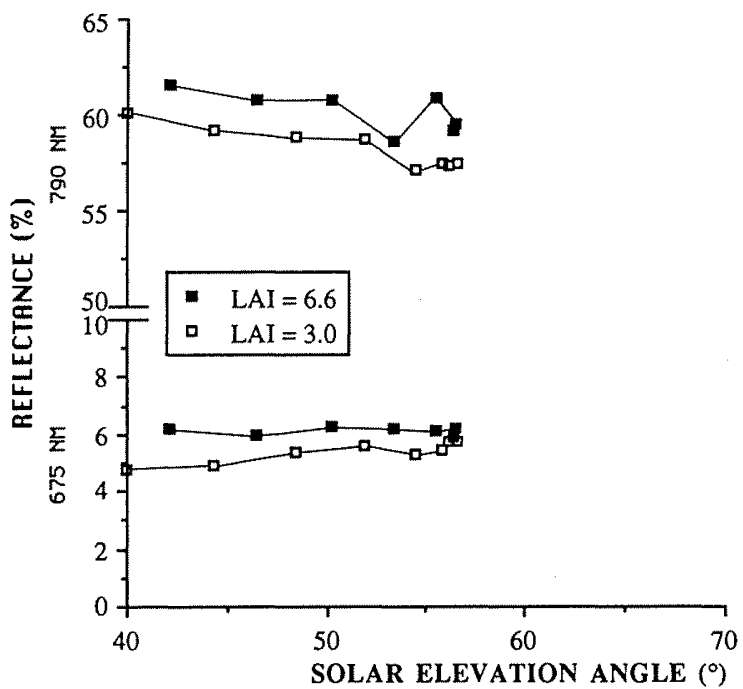


interception of the direct solar radiation by corn canopies compared to sunflower canopies. Larcher (1980), quoting two different experiments realized by Hiroi and Monsi (1966) on sunflower canopies and Allen et al (1964) on corn canopies, has also reported this difference between these two crops. Consequently, the magnitude of the daily variations in the amount of reflecting sunlit soil, then in red reflectances, decreases over corn canopies. For nadir view angle, Ranson et al (1985a) found a strong effect of solar zenith angle on reflectance factors measured in the visible for corn canopies with lower LAI than these found in this study. Pinter et al (1985) and Jackson and Pinter (1986) also found that red reflectances of erectophile wheat canopies were more influenced by the daily variations in sun angles. If solar incident angle had increased up to $90^{\circ}$, corn canopies at low LAI would probably have shown significant red reflectance variations because their perpendicular percentage ground covers are similar to the ones found for sunflower canopies at low LAI (below 100 per cent). On the other hand, corn canopies with lower LAI or larger row width would

A

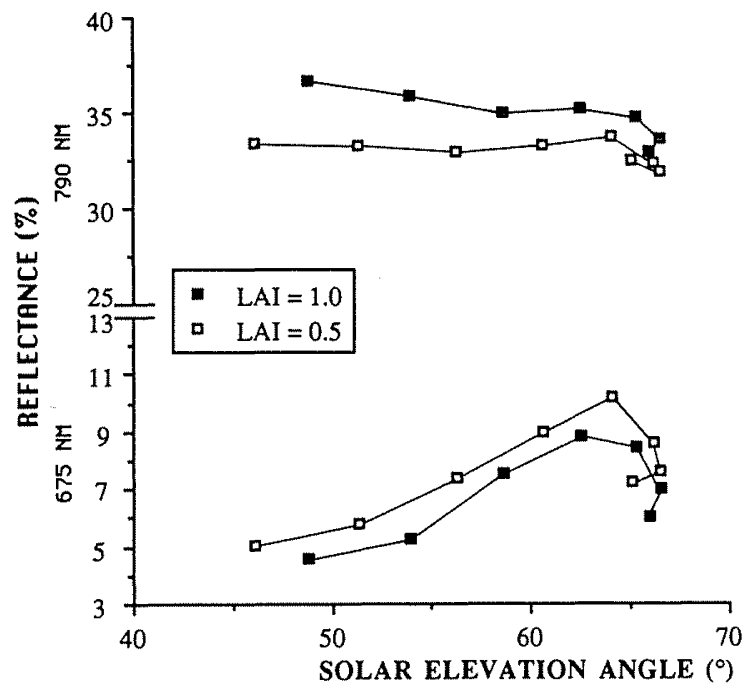

B

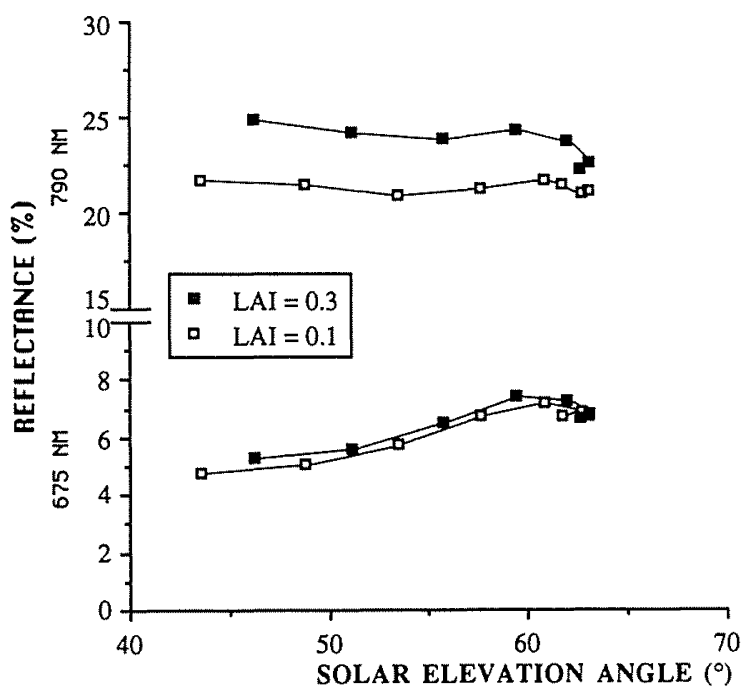

Figure 3

Same as Figure 1, except row azimuth is $150^{\circ}$. Data were collected over wheat canopies with rows $0.35 \mathrm{~m}$ apart:

a) on 14 July at milky ripe; and

b) on 31 July at mealy ripe. also have shown red reflectance variations under the sun angles found in this study, since the proportion of sunlit soil viewed by the sensor would have increased.

The situation is quite different for the near infrared reflectances, these showing larger variations within a day for both high and low LAI canopies. However, the trend of corn and sunflower canopies near infrared reflectance variations found during a day is relatively independent of the amount of green leaves within the canopies, this trend being similar for different LAI values (Figures 1 and 2). This is then the same combination of factors, which explains the daily variations in near infrared reflectances. At low solar elevation angle, the incident rays have more leaf area to cross before reaching the soil as compared to the situation when the sun is high in the sky. The reflectance properties of the green leaves cause the near infrared reflectances to decrease from morning to noon, as the number of leaves encountered by the incident rays decreases, or, in other words, as the probability that the incident rays do not reach a leaf increases. This result agrees with the findings of Jackson et al (1979a) but not with those of Kollenkark et al (1982), who did not find such daily variations in near infrared reflectances collected above soybean canopies with a ground cover of only 64 per cent.

Unlike for corn and sunflowers, canopies with small height do not show constant red reflectance data below $60^{\circ}$ of solar elevation angle (Figures 3, 4, and 5). These increase continuously from morning to noon (true solar time [TST]), then decrease in the afternoon. However, the near infrared reflectances are more variable during a day for the taller crop canopies. Here again, differences in the architecture of the canopies mean differences in the way that daily variations in solar elevation angle influence spectral reflectance data.

An increased variation in red reflectance data is observed from narrow $(0.18 \mathrm{~m})$ to large $(0.35 \mathrm{~m})$ row width for wheat canopies measured at similar growth stages (Figures 3 and 4). This is because the fraction from the sunlit soil reflectance in the total reflectance is smaller for the former canopy. Compared to the other crops with either narrower row width or greater LAI, the values of reflectance data are more affected by the changes in solar elevation angle for the wheat canopies at $0.35 \mathrm{~m}$. Then, the analysis of red reflectances collected over different canopies shows that the influence of sun angles factor on red spectral reflectances increases with row width, even if the species (wheat $0.18 \mathrm{~m}$ vs. wheat $0.35 \mathrm{~m}$ [Figures 3 and 4 respectively]) or LAI (sunflower $0.92 \mathrm{~m}$ vs. corn $0.46 \mathrm{~m}$ [Figures 1 and 2 respectively]) are similar. This effect of row width seems far less important for the near infrared reflectances.

For wheat canopies at $0.17 \mathrm{~m}$ row width, the red reflectance values do not reach their minima when the LAI are greatest (Figure 4). For example, the LAI of the canopy seeded at high density reaches its maximum of 3.8 when the plants were at the boot stage, while red reflectances continued to decrease after this date, even if the LAI was also decreasing (Figures $4 \mathrm{~B}$ vs. $4 \mathrm{C}, \mathrm{D}$ ). This result was obviously not expected, since the values of red reflectances are directly related to the amount of green pigments in the canopies, being smaller when this amount increases (Colwell, 1974). Another unexpected result is that the red reflectance values of barley canopies are the same or greater at the beginning of the growing season than at the end, while their LAI is quite different (Figures 5A, B vs. 5D).

At senescence, the high red reflectance values and the negligible differences between the red reflectances collected above crop canopies of different densities are easily explained by the fact that the absorbing pigments of the visible radiation are strongly 


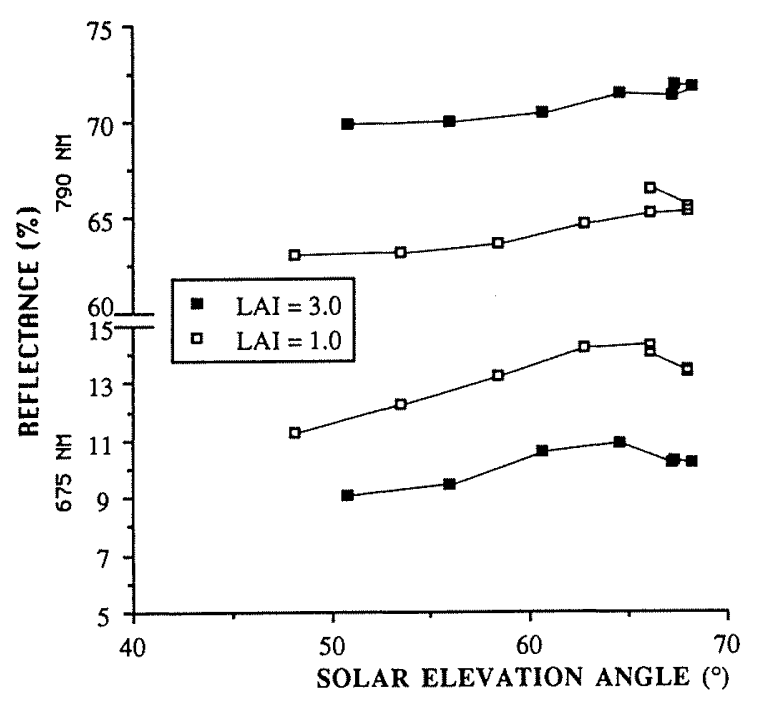

B

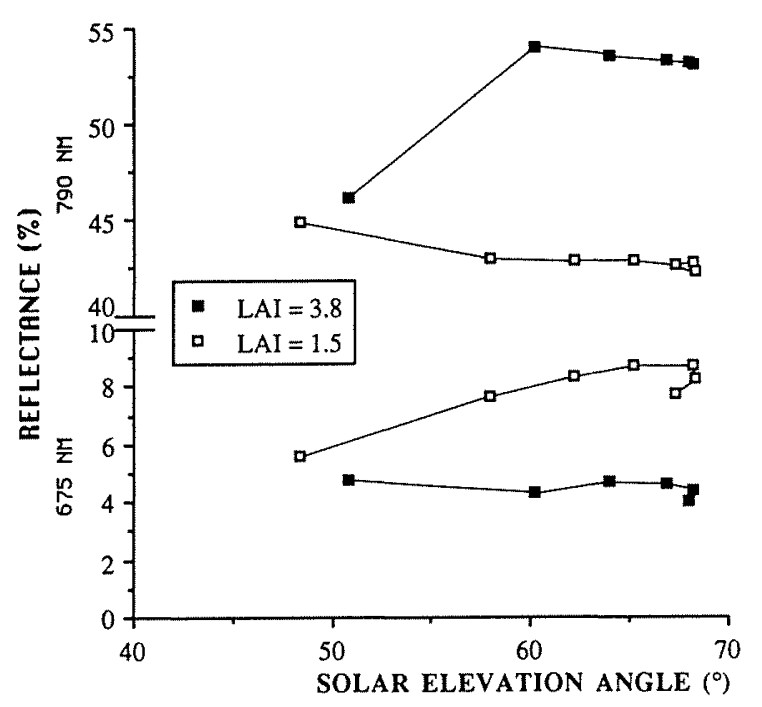

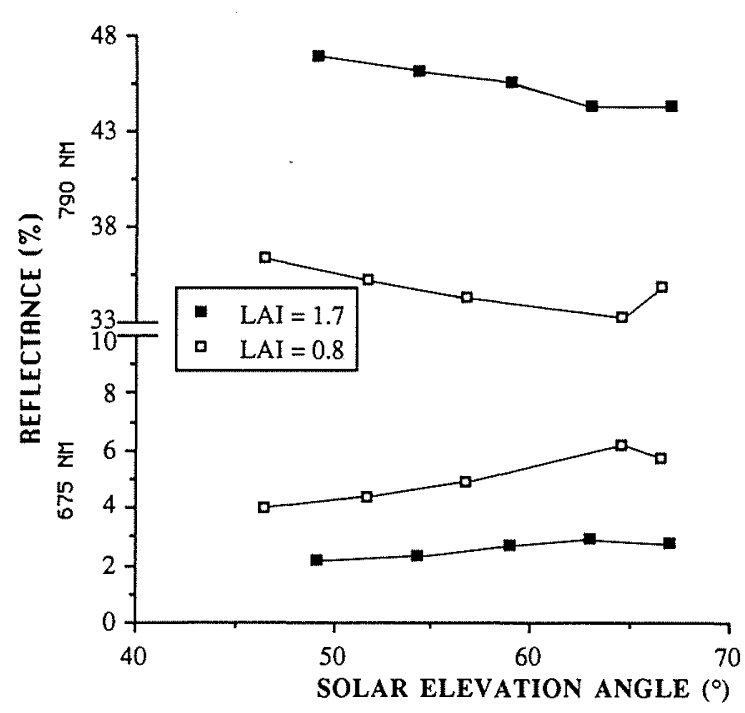

D

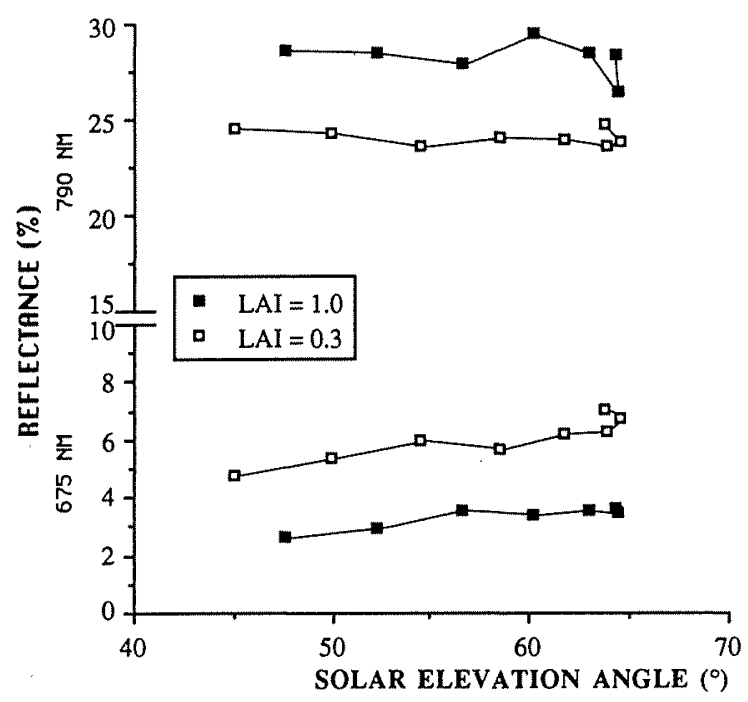

Figure 4

Same as Figure 1, except row azimuth is $150^{\circ}$. Data were collected over wheat canopies with rows $0.18 \mathrm{~m}$ apart:

a) on 13 June at jointing;

b) on 25 June at boot;

c) on 11 July at flowering; and

d) on 25 July at milky ripe.

degraded in all wheat and barley canopies, as indicated by the yellowish colour of the leaves (Figures 4D and 5D). However, at the beginning of the growing season, when the LAI is similar to the value observed later in the summer, the higher red reflectance values for the beginning of the growing season may be explained by the absence of a vertical leaf area distribution, while it was well developed at the middle and at the end (Figures 4A,B and 5A,B). At a low solar elevation angle, a spectroradiometer with a sensor in the nadir position detects more sunlit and shaded soil when the plants are small (height $=0.15 \mathrm{~m}$ ) than when they are tall (height $=0.90 \mathrm{~m}$ ). This results in higher red reflectance values for the former structure, even if the amount of green leaves in the canopy is quite similar or greater. At a high solar elevation angle, the importance of the vertical leaf area distribution decreases. It is then important to take into account this temporal difference in the canopy structure when someone tries to estimate a canopy parameter with either red reflectances or indices using these.

\section{The Direction of Rows and the State of the Sky}

Two other factors related to the direction of the sun rays on the canopies add to the difficulties of interpreting the reflectance data, which was collected over different sun angle values for estimating canopy parameters such as LAI and percentage ground cover: the direction of the rows; and the state of the sky. Figures 1 to 5 show that changes in solar elevation angle ranging from $45^{\circ}$ 
A

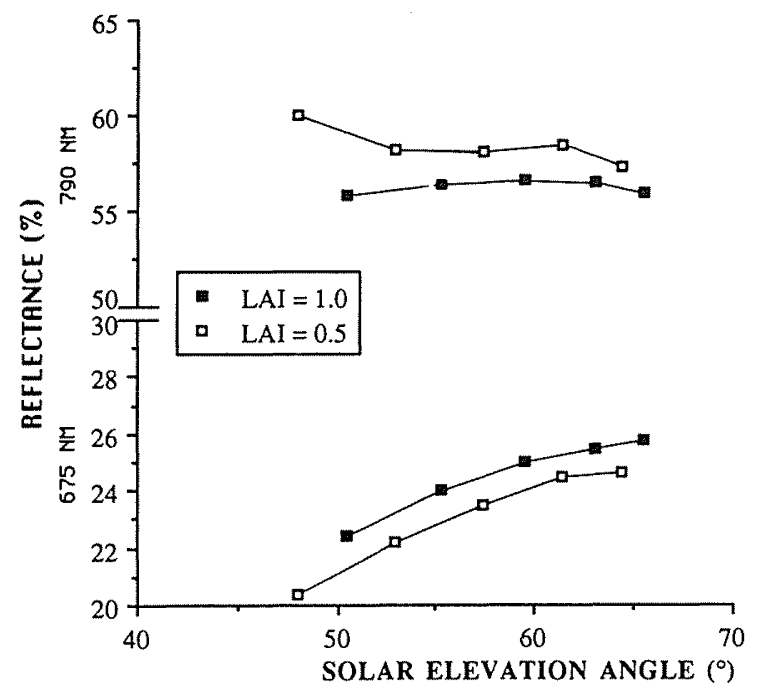

B

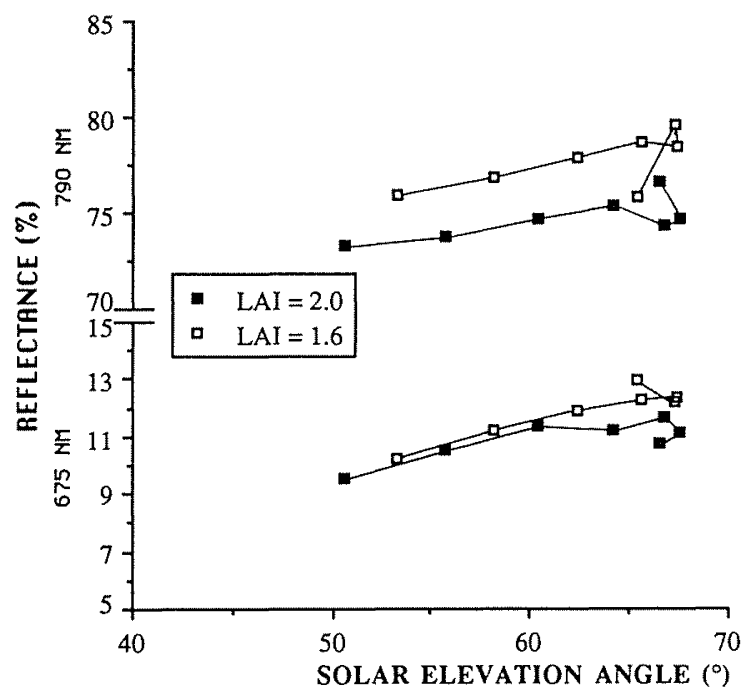

C

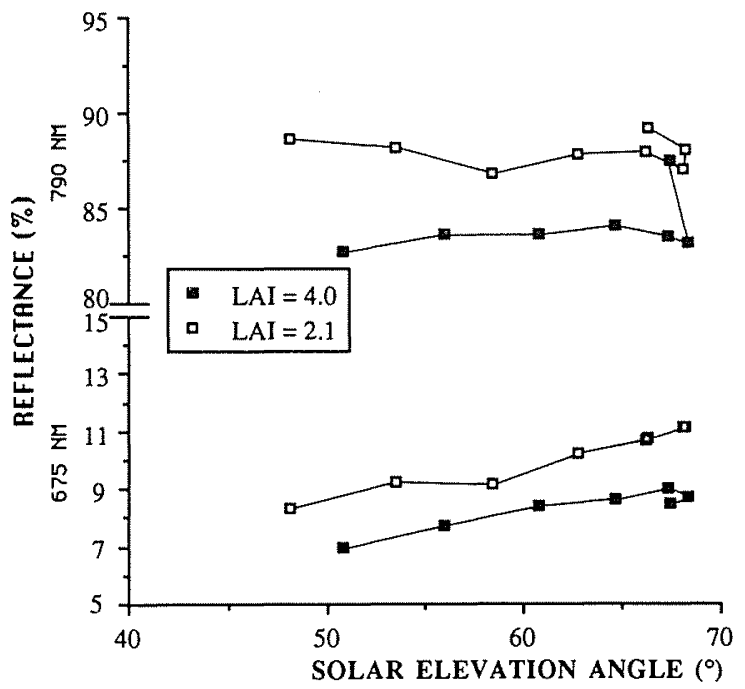

D

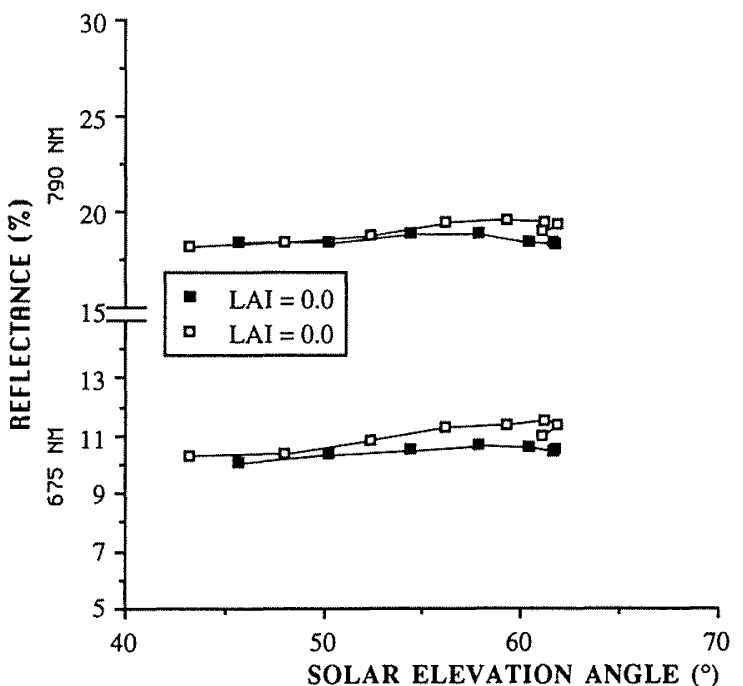

Figure 5

Same as Figure 1, except row azimuth is $150^{\circ}$. Data were collected over barley canopies:

a) on 29 May at tillering;

b) on 05 June at jointing;

c) on 17 June at stem extension; and

d) on 05 August at blister.

to $68^{\circ}$ influence the red and near infrared reflectance values. Most of the plant canopies without rows being almost lambertian for this interval of angles (Egbert et Ulaby, 1972; Smith et al, 1980; Jackson et al, 1979a), the presence of rows in canopies is then an important cause explaining this influence. The presence of rows combined with the changes in solar elevation angle give rise to a difference up to 121 per cent between the minimum and maximum red reflectances collected over a given crop canopy during the same day (Figure 6). Kollenkark et al (1982) and Vanderbilt et al (1981) found that the maximum red reflectance in a row canopy occurred when the sun is in line with the rows. In our experiment, the row direction was NNW-SSE in 1980, introducing an angle of about $30^{\circ}$ from the N-S axis; the sun is in line with rows at approximately 11:00 TST. In 1981, the sunflower crops were planted with N-S rows, the zero difference between the row direction and the sun azimuth being reached at noon TST. Figure 6 shows that the maximum red reflectance values occurred at or near this zero difference for wheat, barley, and sunflower, independently of the direction of the rows. It may also be noted that, except for sunflowers, Figure 6 does not show perfect symmetry between results collected before and after the time of the zero difference. This was expected since solar elevation angle continued to increase after this time, and because other environmental and physiological factors affecting spectral reflectances can also be asymmetric around solar noon. It may also be noted that decreased row width and increased LAI also attenuate the importance of the effect of rows.

The significant effect of solar elevation angle also appears under cloudy and hazy conditions, even if the geometrical 


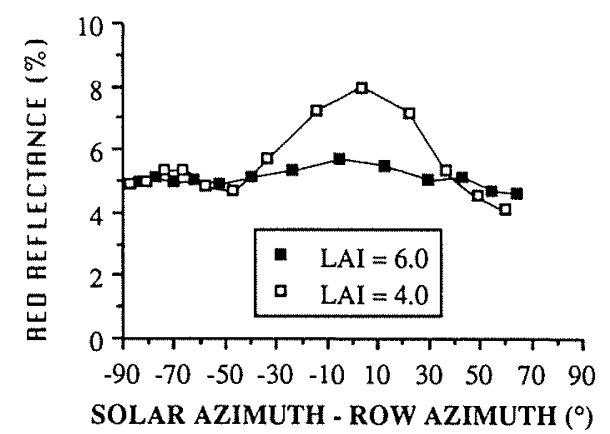

B

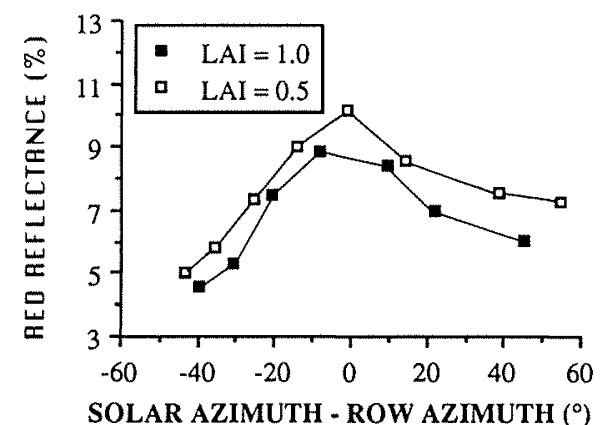

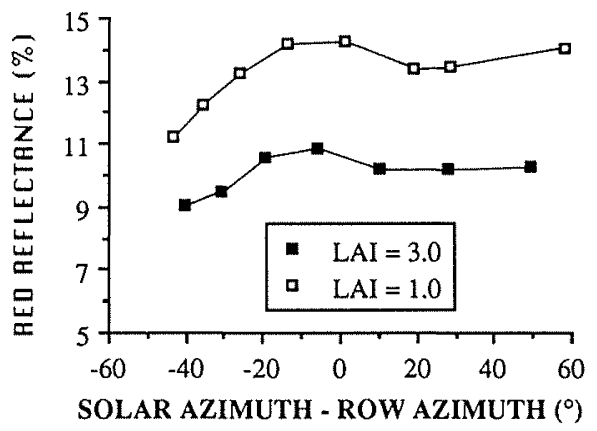

D

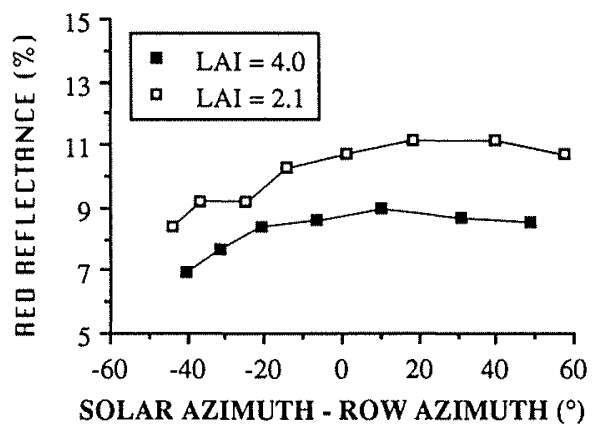

Figure 6

Changes in the red $(675 \mathrm{~nm})$ and near infrared $(790 \mathrm{~nm})$ reflectances plotted against the difference between solar and row azimuth. Data were collected:

a) on 24 July over two sunflower canopies at flowering. Row azimuth is $180^{\circ}$;

b) on $14 \mathrm{July}$ over two wheat canopies with rows $0.35 \mathrm{~m}$ apart at milky ripe. Row azimuth is $150^{\circ}$;

c) on 13 June over two wheat canopies with rows $0.18 \mathrm{~m}$ apart at jointing. Row azimuth is $150^{\circ}$; and

d) on 17 June over two barley canopies at stem extension. Row azimuth is $150^{\circ}$.

Standard deviations are less than or equal to the symbol heights.

properties of the incident beam shift from mainly directional to mainly hemispherical and even if the irradiance values used to calculate the reflectances are not different during the entire period of measurement, unlike the sunny days. For example, this effect is found when red reflectance data are collected above barley on 17 June, a day with high cirrus (Figure 5C). The same results are found for both wavelength bands for the wheat canopy measured on 11 July, when the sky conditions became more and more cloudy from 9.00 TST to noon. The analysis of the reflectance data collected during these two cloudy days demonstrates two facts: 1) the architecture of a canopy (density) remains the major factor accounting for the variability introduced in the near infrared and, to a less extent, red reflectance measurements under a completely diffuse incident radiation regime; and 2) the presence of such a regime does not really change the magnitude of the variations in reflectance data caused by changes in solar elevation angle. This second result disagrees with the assumption that the effect on spectral reflectances of the daily variations in the solar elevation angle is minimized by the increasing amount of diffuse radiation. In reality, the presence of clouds in the atmosphere does not really minimize the effect of the solar elevation angle on the red and near infrared reflectances of a plant canopy, probably because the incident energy measured under the two cloudy conditions encountered in these analyses is provided mainly by the portion of the sky where the solar disc is located (Kondratyev, 1969). Under periods of thicker clouds, the results might be quite different.

The presence of clouds also changes the row effect on red reflectances because the results obtained during a high cirrus cloudy day (barley 06-17, Table 1) do not show as obvious a peak as the three other days (Figure 6). The more hemispherical feature of the incident radiation on cloudy days probably causes this roundedshape red reflectance curve.

With all these results in mind and considering that the relationship between the parameter and the spectral reflectances of a specific vegetation change seasonally (Vinogradov, 1969), one can consider the idea of obtaining a universal equation, which would permit one to precisely calculate the estimated value of an agronomical parameter of a crop canopy only by measuring its reflectances at any time during the growing season or on a given day. If anyone wants to use these measurements for the daily estimation of an agronomic parameter, reflectance data collected at any time on a given day (except near sunrise and sunset) should be normalized to a given moment of a day for given row and sun 
angle effects. The complexity of the angular relationships between the species and their growth stage, the vertical leaf area distribution of the vegetation, the row direction, the state of the sky, and the daily variations in sun angles do not yet permit to find an easy way to normalize the reflectance data collected under different geometrical situations. However, recent works that study some of these relationships conclude that the collection of spectral canopy reflectances with a sensor in off-nadir position would decrease the variability caused by the angular factors (Ranson et al, 1985a,b; Goel and Thompson, 1985; Goel and Grier, 1987).

\section{CONCLUSIONS}

This study quantifies the effect of row direction and variations in solar angles on plant canopy spectral reflectance measurements. The conclusions are as follows:

1. The architecture of the canopy and the amount of green elements in it (LAI) are the facts that account for the largest fraction of the total variability introduced in the plant canopy spectral reflectance measurements, but another non-negligeable fraction is introduced by the daily variations in solar angles.

2. The effect of sun angles varies with the wavelength band, the species, and the row width. The red spectral reflectances are usually more affected than the near infrared ones, while the red reflectances of species with large leaves and a high leaf area density at the top of the canopy are less variables. The larger the row width, the higher the effect of changing sun angles on the reflectance data. The higher the LAI, the smaller the effect of changing sun angles.

3. The magnitude of the differences between reflectances measured at a specific solar elevation angle over two different densities of the same crop species remains rather constant within a given day of reflectance measurements.

4. For barley and wheat, the red reflectance values are higher at the beginning and at the end of the growing season than in the middle when the visible radiation absorbing pigments are at a maximum. Red reflectance values collected at the beginning of the growing season are higher to those collected at the same LAI value later in the summer, after the observation of its maximum. The absence of a vertical leaf area distribution at the beginning of the growing season explains this result.

5. The presence of clouds does not entirely eliminate the effect of daily variations in sun angles on reflectances, even if the regime of irradiation becomes primarily diffuse.

6. The maximum red reflectances always appear when the sun is in line with the rows, i.e., when the azimuth of the sun minus the direction of the rows reaches zero.

7. Finally, this paper demonstrates that in order to properly interpret spectral reflectance data as a measure of LAI for various crops, one should take into account not only the sun elevation and the row direction, but also the species, the wavelength band, the planting pattern, and the sky conditions.

\section{ACKNOWLEDGEMENTS}

We sincerely thank Drs. E.J. Brach and A. Mack of Agriculture Canada, Ottawa, and Dr. G.H. Lemieux of Université du Québec à Chicoutimi for their comments on the manuscript. The support of the Engineering and Statistic Research Service and the Crop Information Program of the Research Branch of Agriculture Canada is much appreciated.

\section{REFERENCES}

(1) Allen, L.H., Yocum, C.S., and Lemon, E.R., (1964) Photosynthesis under field conditions. VII: Radiant energy exchanges within a corn crop canopy and implications in water use efficiency, Agron, J., 56: 253-259.

(2) Asrar, G., Fuchs, M., Kanemasu, E.T., and Hatfield, J.L., (1984) - Estimating absorbed photosynthetic radiation and leaf area index from spectral reflectance in wheat, Agron, J., 76: 300-306.

(3) Asrar, G., Kanemasu, E.T., and Yoshida, M., (1985) Estimates of leaf area index from spectral reflectance of wheat under different cultural practices and solar angle, Remote Sensing Environ., 17: 1-11.

(4) Brach, E.J., Poirier, P., Desjardins, R.L., and Lord, D., (1983) - Multispectral radiometer to measure crop canopy characteristics, Rev. Sci. Instrum., 54: 493-500.

(5) Colwell, J.E., (1974) - Vegetation canopy reflectance, Remote Sensing Environ., 3: 175-183.

(6) Duggin, M.J., (1977) - Likely effects of solar elevation on the quantification of changes in vegetation with maturity using sequential LANDSAT imagery, Appl. Opt., 16: 521-523.

(7) Egbert, D.D., and Ulaby, F.T., (1972) - Effects of angles on reflectivity, Photogr. Eng., 38: 556-564.

(8) Goel, N.S., and Grier, T., (1987) - Estimation of canopy parameters of row planted vegetation canopies using reflectance data for only four view direction, Remote Sensing Environ., 21: 37-51.

(9) Goel, N.S., and Thompson, R.L., (1985) - Optimal solar/viewing geometry for an accurate estimation of leaf area index and leaf angle distribution from bidirectional canopy reflectance data, Int. J. Remote Sensing, 6: 1493-1520.

(10) Hanway, J.J., (1966) - How a corn plant develops, Special Report No. 48, Iowa State University, co-operative extension service, Ames, Iowa.

(11) Hiroi, T., and Monsi, H., (1966) - J. Fac. Sci. Tokyo, 9: 241-285.

(12) Jackson, R.D., and Pinter, P.J., Jr., (1986) - Spectral response of architecturally different wheat canopies, Remote Sensing Environ., 20: 43-56.

(13) Jackson, R.D., Pinter, P.J., Jr., Idso, S.B., and Reginato, R.J., (1979a) - Wheat spectral reflectance: interactions between crop configuration, sun elevation, and azimuth angle, Appl. Opt., 18: 3730-3732.

(14) Jackson, R.D., Pinter, P.J., Jr., Reginato, R.J., and Idso, S.B., (1980) - Hand-held radiometry, USDA, Science and Education Administration, Agricultural Reviews and Manual, ARM-W-19.

(15) Jackson, R.D., Reginato, R.J., Pinter, P.J., Jr., and Idso, S.B., (1979b) - Plant canopy information extraction from composite scene reflectance of row crops, Appl. Opt. 18: 3775-3782. 
(16) Kimes, D.S., Smith, J.A., and Ranson, K.J., (1980) Vegetation reflectance measurements as a function of solar zenith angle, Photogr. Eng. Remote Sensing, 46: 1563-1573.

(17) Knipling, E.B., (1970) - Physical and physiological basis for the reflectance of visible and near infrared radiation from vegetation, Remote Sensing Environ., 1: 155-159.

(18) Kollenkark, J.C., Vanderbilt, V.C., Daughtry, C.S.T., and Bauer, M.E., (1982) - Influence of solar illumination angle on soybean canopy reflectance, Appl. Opt., 21: 1179-1184.

(19) Kondratyev, K.Ya., (1969) - Radiation in the atmosphere, Academic Press, New York, 912 pp.

(20) Larcher, W., (1980) - Physiological Plant Ecology, $2^{\text {nd }}$ ed., Springer-Verlag, Berlin-Heidelberg, New York, 303 pp.

(21) Large, E.C., (1954) - Growth stages in cereals: illustration of the Feekes scale, Plant Pathol., 3: 128-129.

(22) Lord, D., Desjardins, R.L., and Dubé, P.A., (1985a) Influence of wind on crop canopy reflectance measurements, Remote Sensing Environ., 18: 113-123.

(23) Lord, D., Desjardins, R.L., Dubé, P.A., and Brach, E.J., (1985b) - Variations of crop canopy spectral reflectance measurements under changing sky conditions, Photogr. Eng. Remote Sensing, 51: 689-695.

(24) Nicodemus, F.E., Richmond, J.C., Hsia, J.J., Ginsberg, I.W., and Limperis, T., (1977) - Geometrical considerations and nomenclature for reflectance, National Bureau of Standards, Monograph 160, Washington, D.C., 52 pp.

(25) Pinter, P.J., Jr., Jackson, R.D., and Ezra, C.E., (1985) Sun-angle and canopy-architecture effects on the spectral reflectance of six wheat cultivars, Int. J. Remote Sensing: 6: 1813-1825.

(26) Ranson, K.J., Biehl, L.L., and Bauer, M.E., (1985a) Variation in spectral response of soybeans with respect to illumination, view and canopy geometry, Int. J. Remote Sensing, 6: 1827-1842.

(27) Ranson, K.J., Daughtry, C.S.T., Biehl, L.L., and Bauer, M.E., (1985b) - Sunview angle effects on reflectance factors of corn canopies, Remote Sensing Environ., 18: 147-161.

(28) Richardson, A.J., Wiegand, C.L., Gausman, H.W., Cuellar, J.A., and Gerbermann, A.H., (1975) - Plant, soil and shadow reflectance components of row crops, Photogr. Eng. Remote Sensing, 41: 1401-1407.

(29) Ross, J., (1976) - Radiative transfer in plant communities, pp. 13-110 In J.L. Monteith (ed.), Vegetation and The Atmosphere. Academic Press, London.

(30) Schneiter, A.A., and Miller, J.F., (1981) - Description of sunflower growth stages, Crop Sci., 21: 901-903.

(31) Smith, J.A., Lie Lin, T., and Ranson, K.J., (1980) - The lambertian assumption and LANDSAT data, Photogr. Eng. Remote Sensing, 46: 1183-1189.

(32) Vanderbilt, V.C., Kollenkark, J.C., Biehl, L.L., Robinson, B.F., Bauer, M.G., and Ranson, K.J., (1981) - Diurnal changes in reflectance factor due to sun-row direction interactions. AgRISTARS Technical Report SR-P1-04140, Laboratory for Applications of Remote Sensing, Purdue University, West Lafayette, Indiana. $10 \mathrm{pp}$.
(33) Vinogradov, B.V., (1969) - Remote sensing of the arid zone vegetation in the visible spectrum for studying the productivity, pp. 1237-1250 In Proc. Sixth Int. Symp. on Remote Sensing of Environ., Univ. Michigan, Ann Arbor.

(34) Walraven, R., (1978) - Calculating the position of the sun, Solar Energy, 20: 393-397.

(35) Weiser, R.L., Asrar, G., Miller, G.P., and Kanemasu, E.T., (1986) - Assessing grassland biophysical characteristics from spectral measurements, Remote Sensing Environ., 20: 141-152. 